\title{
David Oliver: Are we rushing patients home before they're ready?
}

\section{David Oliver consultant in geriatrics and acute general medicine}

Berkshire

Emergency readmission rates (defined as unplanned readmissions to hospital within 30 days of leaving) are now rising twice as quickly as overall emergency admissions. In June 2018 an analysis by QualityWatch (a Nuffield Trust and Health Foundation collaborative) showed a $19.2 \%$ rise in readmissions from 2010-11 to 2016-17, compared with a $10.5 \%$ rise in overall emergency admissions. ${ }^{1}$

The researchers noted that some coding and counting issues confounded data interpretation and accuracy, given that routine hospital episode statistics (HES) were used. And, although NHS Digital stopped reporting readmission rates in 2013-14_making triangulation hard-these are big numbers, as over a million patients a year are reportedly readmitted. The trends are consistent with recent analyses from HealthWatch England and the National Audit Office. ${ }^{23}$ The highest percentage of readmissions and the sharpest rise was in patients returning within 24 hours of discharge.

The QualityWatch report returned to a methodology the Nuffield Trust used in 2014 to classify common causes of emergency readmission, including "potentially preventable" ones. ${ }^{4}$ Such readmissions had risen $41.3 \%$ over the seven years studied, from 130760 to 184763 . This definition included venous thromboembolism, pressure sores, hospital acquired infections, pharmacological iatrogenesis, and recognised complications of medical procedures.

The authors acknowledged that the term "potentially preventable" would require much more detailed structured case note review to determine how preventable the complications were. It's striking that these complications were not generally coded on initial discharge from hospital. Is it really the case (especially in earlier readmissions) that issues such as pressure sores weren't even noticed? I doubt that HES can give us such detail. Of course, we have evidence based guidelines for preventing such complications $\mathrm{s}^{5-9}$ —and it might be interesting to compare each hospital's organisational prevention approaches (for instance, from Care Quality Commission reports or national clinical audits) with those "potentially preventable" readmission rates.
Readmissions can result from relapses of existing long term conditions, new and unrelated illness, inadequately provisioned or responsive community support and follow-up, help seeking behaviour of patients' families or care workers, or hospitals sending patients home unstable or without sufficient planning or communication. They also result from respecting patients' right to take risk and their preference to be at home and not in hospital. But in general they reflect a systemwide problem, not simply the quality of hospital care. ${ }^{1011}$

There may be numerous local case studies on interventions to reduce readmissions, but we currently have no consistent evidence from systematic review of clinical trials, ${ }^{12}$ although some interventions in specific groups (for instance, cardiac failure nurse practitioners) have been proved consistently. ${ }^{13}$ Nor is there a consistent link between short stays and readmission rates, amid many potential confounders.

It's getting ever harder to hang on to patients for that extra day or two, just to be sure

Longer stays may expose patients to a greater risk of complications, worsening mobility, and loss of independence. ${ }^{14}$ Shorter stays may sometimes represent better organised care, rehabilitation, and discharge planning or better access to stepdown community services. In some quality improvement studies on improving patient flow and reducing bed occupancy and length of stay, no increase in readmissions was seen. ${ }^{15}$

My gut feeling on this issue tallies with other experienced clinicians I've spoken to, although I've no scientific basis for it. We seem under relentless pressure to discharge patients in their recovery phase, earlier and earlier.

At the same time we're dealing with falling bed numbers, rising admission rates, more beds being put out of action by delayed transfers of care, and community and primary care services coming under increasing strain. It's getting ever harder to hang on to patients for that extra day or two, just to be sure. On the other hand, although readmissions can be very distressing for patients and families, so can being stranded in hospital: maybe 
readmission is the price to be paid. I wonder whether readers agree.

Competing interests: See www.bmj.com/about-bmj/freelance-contributors/davidoliver.

Provenance and peer review: Commissioned; not externally peer reviewed.

1 Morris J. Emergency readmissions: Trends in emergency readmissions to hospital in England. QualityWatch 23 May 2018. http://www.qualitywatch.org.uk/blog/emergencyreadmissions-trends-emergency-readmissions-hospital-england.

2 HealthWatch. What do the numbers say about emergency readmissions to hospital? 26 Oct 2017. https://www.healthwatch.co.uk/resource/what-do-numbers-say-about-emergencyreadmissions-hospital.

3 National Audit Office. Reducing emergency admissions. 2 March 2018. https://www.nao. org.uk/report/reducing-emergency-admissions/

4 Nuffield Trust. Classifying emergency 30-day readmissions in England using routine hospital data 2004-2010: what is the scope for reduction? 26 March 2014. https://www. nuffieldtrust.org.uk/research/classifying-emergency-30-day-readmissions-in-englandusing-routine-hospital-data-2004-2010-what-is-the-scope-for-reduction.

5 National Institute for Health and Care Excellence. Pneumonia: diagnosis and management of community- and hospital-acquired pneumonia in adults. Dec 2014. https://www.nice. org.uk/guidance/CG191.

6 NHS Improvement. Stop the pressure. http://nhs.stopthepressure.co.uk/.

7 BMJ Best Practice. VTE prophylaxis. https://bestpractice.bmj.com/topics/en-gb/1087.
8 NHS England. Venous thromboembolism (VTE) risk assessment. https://www.england. nhs.uk/statistics/statistical-work-areas/vte/.

9 Mehta Y, Gupta A, Todi S, etal . Guidelines for prevention of hospital acquired infections. Indian J Crit Care Med 2014;18:149-63. https://www.ncbi.nIm.nih.gov/pmc/articles/ PMC3963198/. 10.4103/0972-5229.128705 24701065

10 Department of Health. Payment by results guidance for 2012-13. Feb 2012. https://www. gov.uk/government/collections/payment-by-results-2012-13.

11 Oliver D. David Oliver: Who is to blame for older people's readmission?BM 2015;351:h4244. 10.1136/bmj.h4244 26253123

12 Kripalani S, Theobald CN, Anctil B, Vasilevskis EE. Reducing hospital readmission rates: current strategies and future directions. Annu Rev Med 2014;65:471-85. https://www.ncbi. nIm.nih.gov/pmc/articles/PMC4104507/. 10.1146/annurev-med-022613-090415 24160939

13 Lambrinou E, Kalogirou F, Lamnisos D, Sourtzi P. Effectiveness of heart failure management programmes with nurse-led discharge planning in reducing re-admissions: a systematic review and meta-analysis. Int J Nurs Stud 2012;49:610-24. https://www. sciencedirect.com/science/article/pii/S0020748911004238. 10.1016/j.jinurstu.2011.11.002 22196054

14 Oliver D. David Oliver: Fighting pyjama paralysis in hospital wards. BMJ 2017;357:j2096. https://www.bmj.com/content/357/bmj.j2096. 10.1136/bmj.j2096 28465317

15 Silvester KM, Mohammed MA, Harriman P, Girolami A, Downes TW. Timely care for frail older people referred to hospital improves efficiency and reduces mortality without the need for extra resources. Age Ageing 2014;43:472-7. https://www.ncbi.nlm.nih.gov/ pubmed/24222658. 10.1093/ageing/aft170 24222658

Published by the BMJ Publishing Group Limited. For permission to use (where not already granted under a licence) please go to http://group.bmj.com/group/rights-licensing/ permissions 